\title{
Wrap it up! Should we take it?
}

\author{
Harish Seethamraju, $\mathrm{MD},{ }^{\mathrm{a}}$ and Subroto Paul, $\mathrm{MD}, \mathrm{MPH}^{\mathrm{b}, \mathrm{c}}$
}

From the ${ }^{\mathrm{a} D e p a r t m e n t}$ of Medicine and Cardiothoracic Surgery, Albert Einstein College of Medicine, Bronx, NY; Departments of ${ }^{b}$ Surgery and ${ }^{\mathrm{c}}$ Cardiothoracic Surgery, Saint Barnabas Medical Center, Newark Beth Israel Hospital, RWJBarnabas Health, Livingston, NJ.

Disclosures: Authors have nothing to disclose with regard to commercial support.

Received for publication Feb 28, 2018; accepted for publication March 6, 2018; available ahead of print April 5, 2018.

Address for reprints: Subroto Paul, MD, MPH, Department of Cardiothoracic Surgery, RWJBarnabas Health, 94 Old Short Hills Rd, Suite 1172, Livingston, NJ 07039 (E-mail: Subroto.Paul@rwjbh.org).

J Thorac Cardiovasc Surg 2018;155:2760-1

$0022-5223 / \$ 36.00$

Copyright $(\underset{c}{ } 2018$ by The American Association for Thoracic Surgery

https://doi.org/10.1016/j.jtcvs.2018.03.033

Long-term outcomes after lung transplantation remain suboptimal. Although the 1-year survival is nearly $80 \%$, the 5 year survival is closer to $50 \%$, which is significantly less than for other solid organ transplants. ${ }^{1}$ Chronic lung allograft dysfunction and its clinical equivalent, bronchiolitis obliterans syndrome, account for the leading cause of graft dysfunction. Gastroesophageal reflux disease has been suggested to be a non-immune related cause in the development of bronchiolitis obliterans syndrome. ${ }^{2}$ Treating and preventing reflux with a fundoplication has become part of the standard workup for lung transplant recipients; with centers offering fundoplication before or after transplantation.

In their study in this issue of the Journal, Roy and colleagues $^{3}$ attempt to determine the optimal timing of anti-reflux surgery in patients who had undergone lung transplantation. Their main finding is that early fundoplication $(<6$ months after transplantation) results in improved forced expiratory volume in 1 second at 5 years. There were no differences in overall survival, rate of rejection, or freedom from bronchiolitis obliterans between the 2 groups. $^{3}$

The study is limited mainly by its retrospective nature. Confounding by acute events not accounted for in the statistical model may have skewed the results. In addition, the forced expiratory volume in 1 second after lung transplant is related to the donor size, sex, and genetic background. Comparing these variables that are donor specific in both groups could shed more light on the impact of fundoplication. Inclusion of the forced vital capacity numbers in the 2 groups would be very helpful in determining the presence or absence of restrictive chronic lung allograft dysfunction. A prospective trial would be preferable but likely unrealistic to complete given variations in waiting time and patterns of care among the various transplant centers. Nevertheless, this large study confirms previous studies and thereby validates current practice to screen for and treat reflux in those with endstage lung disease. .-6 $^{4-2}$

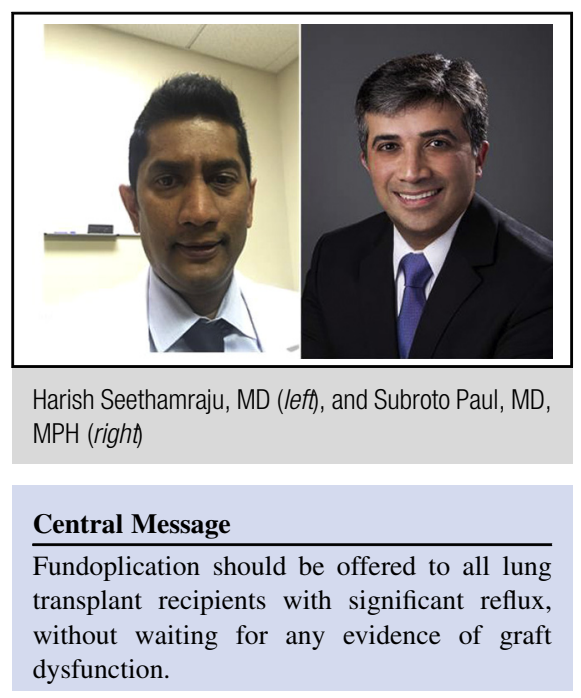

See Article page 2762.

The study also raises interesting questions. The patients who benefited the most from fundoplication in this study are older patients with higher lung allocation scores and DeMeester scores greater than 20. Would these patients benefit more if fundoplication were done before transplantation? Roy and colleagues ${ }^{3}$ perform fundoplication after the transplant because they have short list times and do not want to delay transplantation. The benefit of fundoplication may be magnified if it is performed earlier, however, positively affecting overall survival or survival without bronchiolitis obliterans. Intuitively, it seems as though this should be the case. The immunologic situation after lung transplantation is more complex, however, with interactions between the body and the environment that we have yet to understand. It is therefore unlikely that a simple solution exists. Until then, we have evidence that fundoplication benefits lung transplant recipients with reflux and should be performed. The optimal timing is yet not known.

\section{References}

1. Scientific Registry of Transplant Recipients. 2016 annual data report. Available at: http://srtr.transplant.hrsa.gov/annual_reports/Default.aspx. Accessed February 2018.

2. Hathorn KE, Chan WW, Lo WK. Role of gastroesophageal reflux disease in lung transplantation. World J Transplant. 2017;7:103-16.

3. Roy SB, Elnahas S, Serrone R, Haworth C, Olson MT, Kang P, et al. Early fundoplication is associated with slower decline in lung function after lung transplantation in patients with gastroesophageal reflux disease. J Thorac Cardiovasc Surg. 2018;155:2762-71.e1.

4. Robertson AG, Krishnan A, Ward C, Pearson JP, Small T, Corris PA, et al. Antireflux surgery in lung transplant recipients: outcomes and effects on quality of life. Eur Respir J. 2012;39:691-7. 
5. Hartwig MG, Anderson DJ, Onaitis MW, Reddy S, Snyder LD, Lin SS, et al. Fundoplication after lung transplantation prevents the allograft dysfunction associated with reflux. Ann Thorac Surg. 2011;92:462-8; discussion; 468-9.
6. Davis RD Jr, Lau CL, Eubanks S, Messier RH, Hadjiliadis D, Steele MP, et al Improved lung allograft function after fundoplication in patients with gastroesophageal reflux disease undergoing lung transplantation. J Thorac Cardiovasc Surg. $2003 ; 125: 533-42$ 